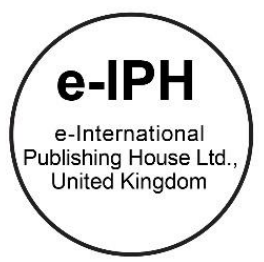

\title{
Spatial and Sociocultural Aspects of Urban Mosque Open Spaces in Kuala Lumpur, Malaysia: A mixed-method approach
}

\author{
Norhanis Diyana Nizarudin* \\ Edinburgh School of Architecture and Landscape Architecture, Edinburgh College of Art, The University of Edinburgh, 74 Lauriston PI, Edinburgh EH3 9DF, \\ United Kingdom
}

\begin{abstract}
This paper highlights the application of mixed-method in discovering different perspectives of socio-culture, spatial interactions and behaviours, as well as activities of the multicultural community at selected urban mosque open spaces as part of civic open spaces in Kuala Lumpur, Malaysia. Through systematic observation with behaviour mapping, and focus group discussions, the value of this research lies in representing the urban mosque open spaces as a civic space in enhancing the socio-cultural integration in the society and improving the quality of urban life.

(C) 2016. The Authors. Published for AMER ABRA by e-International Publishing House, Ltd., UK. Peer-review under responsibility of AMER (Association of Malaysian Environment-Behaviour Researchers), ABRA (Association of Behavioural Researchers on Asians) and cE-Bs (Centre for Environment-Behaviour Studies), Faculty of Architecture, Planning \& Surveying, Universiti Teknologi MARA, Malaysia.
\end{abstract}

Keywords: Urban mosques open spaces; spatial interactions; socio-culture; multicultural community

\section{Introduction}

Mosque is a central and sacred worship place that embraces physical, spiritual and mutual accountabilities in Islam (Mohamad Tajuddin, 2010). Besides of functioning as a religious and spiritual institution for Muslims, the original idea and concept of the mosque development was suggested as an ideal public space for various communal activities (Baharudin \& Ismail, 2014; Omer, 2013). It is also believed that the utilisation of the mosque as a community place should be all-inclusive. Without limiting its function only for the Muslim community, the mosque should be an ideal place that allows the non-Muslim community to take part in any social or communal activities together with the Muslim community (Ismail, 2002; Najafi and Sharif, 2011). Previous research had emphasised various interests in mosque-based studies such as the importance, functions and roles of the mosque as a community place; the mosque architectural design implications towards the community (Mohamad Rasdi and Utaberta, 2010), place attachment and users' experience of the mosque (Mohyuddin and Lamit, 2008; Najafi and Mohd Shariff, 2011) and spiritual meanings of the mosque spaces towards the community (Dewiyanti and Kusuma, 2012). Little interest has been placed on the importance of mosque open spaces as civic open spaces for public access in the city. Thus, this

\footnotetext{
${ }^{*}$ Corresponding author. Tel.: +447707731332
}

E-mail address: norhanis.nizarudin@ed.ac.uk

(c) 2016. The Authors. Published for AMER ABRA by e-International Publishing House, Ltd., UK. Peer-review under responsibility of AMER (Association of Malaysian Environment-Behaviour Researchers), ABRA (Association of Behavioural Researchers on Asians) and cE-Bs (Centre for EnvironmentBehaviour Studies), Faculty of Architecture, Planning \& Surveying, Universiti Teknologi MARA, Malaysia. 
paper attempted to explore the application of mixed-method in bridging the gap between how the provision of the mosque open spaces could achieve the intercultural spaces concept and meet the needs of a multicultural society as suggested by Sirat and Abdullah (2007) in the context of Kuala Lumpur, Malaysia.

\section{Mosque in the Malaysian Context}

Department of Urban and Rural Planning Malaysia (1997) suggests that there are few typologies of Muslim worship institutes in Malaysia. Table 1 below depicts their typology followed by level of development, settlements hierarchy and also the functions of each worship place:

Table 1. Types of Muslim worship place in Malaysia (Department of Urban and Rural Planning Malaysia, 1997)

\begin{tabular}{llll}
\hline TYPOLOGY & LEVEL & SETTLEMENTS HIERARCHY & FUNCTIONS \\
\hline National mosque & National & City centre & \\
State mosque & Capital city & \\
& & National federal territory & \\
District mosque & District & State federal territory & Muslims' house of worship and \\
Sub-district mosque & Sub-district/rural area & Main local district & social integration centre \\
& & Rural development area & \\
& & Villages & \\
\hline $\begin{array}{l}\text { Surau, madrasah, } \\
\text { musolla }\end{array}$ & Neighbourhood & Neighbourhood & Surau: as worship place and \\
& Village & Villages & rigious education centre. \\
& Housing area & Small neighbourhood & Madrasah: as a religious education \\
& Commercial area & Airports & accommodations. It is also known \\
& & Bus hub & as a monastic mosque. \\
& & & Musolla: as worship place only.
\end{tabular}

Based on the table presented above, it can be seen that different mosques have different duties and responsibilities at various level of development and settlement hierarchy in Malaysia. Nevertheless, for this study, Kuala Lumpur urban area was specifically chosen because it is the capital city of Malaysia. Based on this classification above, three urban mosques were selected for this study - National Mosque, Kuala Lumpur (national level); Abu Ubaidah Al-Jarah Mosque, Kuala Lumpur (district level); and Al-Ghufran Mosque, Kuala Lumpur (sub-district or neighbourhood level). These mosques were selected as the study areas because they play vital roles in each of the settlement hierarchy, and they act as distinctive focal points for the public. Furthermore, they are chosen based on the hierarchical level in order to explore the similarities and differences each mosque would offer to the community. Figure 1(a), (b) and (c) below show the selected urban mosques for this study. 

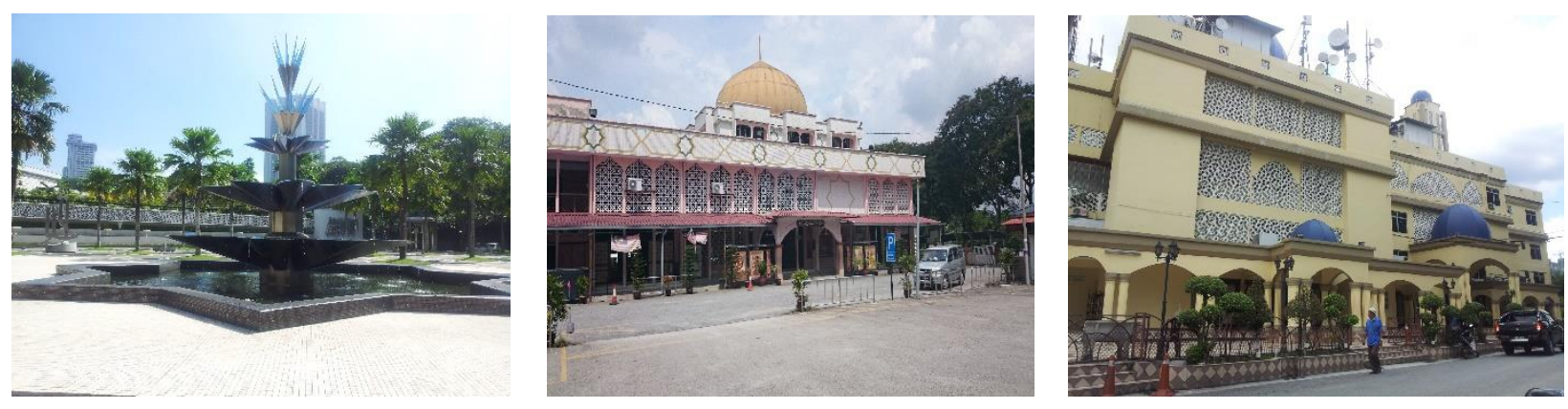

Fig. 1. (a) National Mosque, Kuala Lumpur; (b) Abu Ubaidah Al-Jarah Mosque, Kuala Lumpur; (c) Al-Ghufran Mosque, Kuala Lumpur

\section{Mosque Open Spaces as Civic Open Spaces}

Omer (2009) and Tamuri, Ismail, and Jasmi (2012) had suggested that since the great Islamic era, the mosque had been seen as a nucleus for the Muslim community where communal activities and integration were transpired. Furthermore, the mosque itself has been categorized as an important civic spaces in town or city (Fukami and Sato, 2012; Musytari and Jasmi, 2008). Also considered as open spaces for public access and enjoyment in the city centres, civic open spaces often displayed in the form of a square, plaza and open spaces of the public, institutional and private building like a mosque, church, hospital, school and lot more (Mansor, Zakariya, and Harun, 2015). This kind of spaces should afford as an urban environment enjoyment platform for wide range of social activities, and most importantly of all, a place for movement (Ward Thompson, 2002). It stands as a reflection of a city's spatial and social organisation, and that may contribute to social reproduction and change (Vasilevska, 2012). Thus, the mosque open spaces could be a civic place where it be a vital society meeting point to enjoy besides serving the religious activities. A primary set of criteria has been established to recognise the relationship between mosque as a design element and the social function as shown in Figure 2 below (Mohamed Kamal Ismail, 2010).

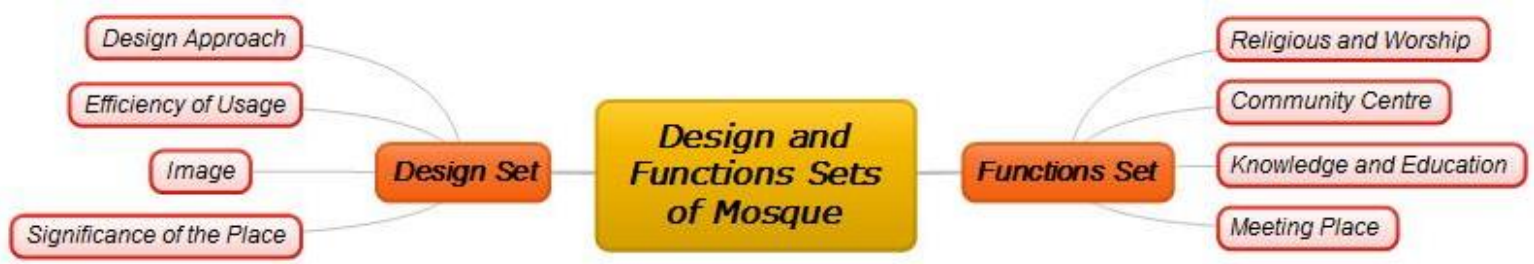

Fig. 2. Design and functions set of the mosque (Mohamed Kamal Ismail, 2010)

Based on the previous figure, design and duties of the mosque are interrelated to each other. Each subset has its significance roles in establishing the mosque as a civic place. In the traditional time, courtyards were part of the mosque design that functioned as important social and communal spaces for the evolving community (Aazam, 2005; Sirat and Abdullah, 2007). The courtyards that adjoined the mosque were fundamentally used as communal spaces, where social and civic activities were normally conducted by all sectors of the local community. As such, it can be presumed that, without those elements, the mosque itself could not possibly function as a communal and intercultural space for the local community. Nevertheless, it is evident that, even in the absence of the courtyards, the qualities and characters of communal and intercultural spaces do seem to exist at the mosques in Malaysia, particularly in the Kuala Lumpur area Sirat and Abdullah (2007). Hence, in Malaysia, the types of communal or intercultural spaces associated with the mosque are often varied, not necessarily being a courtyard. They may include other open spaces around the mosque, adjacent to the mosque and other influential spaces that may not formally be part of the mosque. About this, (Mohamad Rasdi, 2010) raises an issue regarding the mosque open spaces in Malaysia being frequently designed and ornamented with sculptures, decorative gardens and car parks. In other words, it can be said that there 
were little attempts to transform the mosque open spaces into attractive and valuable public open spaces, which would encourage intercultural interactions among the community. Despite merely being beautified for aesthetical reasons, the mosque open spaces should be acknowledged and appreciated for their distinctive environmental and societal functions. As stated by Sirat and Abdullah (2007), the provision of such spaces should meet the needs of multicultural and multi-ethnic societies as there is none legislation that forbids the non-Muslim community to play a part in social activities in the compounds or any spaces around the mosque.

It is very vital to understand the roles of mosques about local communities. A project named 'The Mosque in Community' has been done by Mosque and Imams Advisory Boards (2011). They have come out with significant recommendations in reviving the roles of mosques in the local community:

- The mosque should engage with other faith communities, but also do so with a range of denominations within faith communities to ensure diversity of activities and engagement;

- The mosque should promote classes and training, such as health and well-being classes; as well as sports and fitness classes as part of the healthy social activities;

- The mosque should be connected to the wider non-Muslim community through (i) inclusive interaction and inviting followers of other religions to visit the mosque, (ii) taking mosque users and committee members to visit other places of worship, and (iii) welcoming the local non-Muslims to the mosque to join any events or celebrations.

- The mosque should organise social action days for local areas, which can help to support relationships with wider communities. This might include social action days or in other words, charity session for helping the homeless and many more.

\section{Application of Methods}

This study involves a case study design with a combination of qualitative and quantitative data collection (mixed-methods). It involves a primary method which are systematic observations with behaviour mapping and supported by focus group discussions as the qualitative method. The selected methods for this study are explained as follows:

\subsection{Systematic observation with behaviour mapping}

Systematic observation with behaviour mapping is a part of the quantitative data collection for this study. Bryman (2012) suggests that it is a technique where the researcher employs formulated rules and protocols for the observation and recording of behaviour in relation to features of the physical environment. These protocols are then described in an observation schedule or also known as a checklist. Other instruments required for this observation with behaviour mapping includes site plans, stationaries, audio and visual recording equipment. This type of observation also involves walking through the open spaces according to several intervals of time. In the case of this study, time intervals were determined which partly adapting the Muslim prayer times. During the observation, behaviour mapping is employed to record the users' location and behavioural patterns in the predetermined open spaces (Cosco, Moore, and Islam, 2010; Salama and Salama, 2008). This technique provides researchers with an innovative method of assessing behaviour linked to the detailed physical characteristics of open spaces and outdoor areas (Moore and Cosco, 2010). Few assistants were assigned to assist the researcher in conducting the observation according to the predetermined day and time intervals. The researcher and the assistants observed the mosque open spaces and manually mapped the spatial occupancy of the spaces based on several variables - users' genders, ethnicities, age groups and activities. A set of coding and symbols has been established by adopting and adapting the coding set used by (Marušic and Marušić, 2012). Figure 3(a) below shows the example of coding and symbols from the previous research. Meanwhile, Figure 3(b) displays the improvised version of coding and symbols used by the researcher during the pilot study for this research: 

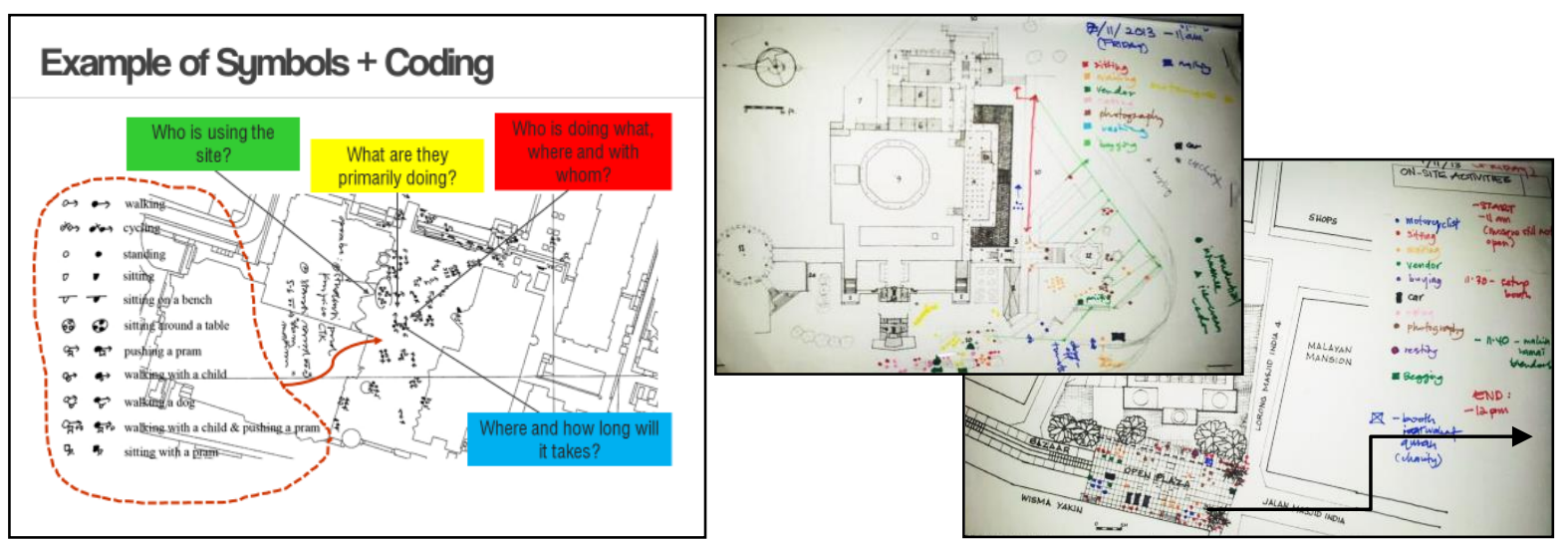

Fig. 3. (a) Example of symbols and coding by (Marušić \& Marušić, 2012); (b) symbols and coding used by the researcher

After the data had been gathered in the form of physical maps as featured in Figure $3(b)$, the data was then digitized into a spatial analysis software called ArcGIS. It has been chosen to be used for analysis tool due to its capability in sorting the spatial data into layers and providing descriptive statistics that helps the researcher to recognise the spatial occupancy of the multicultural community at the mosque open spaces. Furthermore, maps produced by ArcGIS are simple yet comprehensive which helps the researcher to visualize the data in a simpler way. Figure 4 below shows the data after being digitized in the ArcGIS:

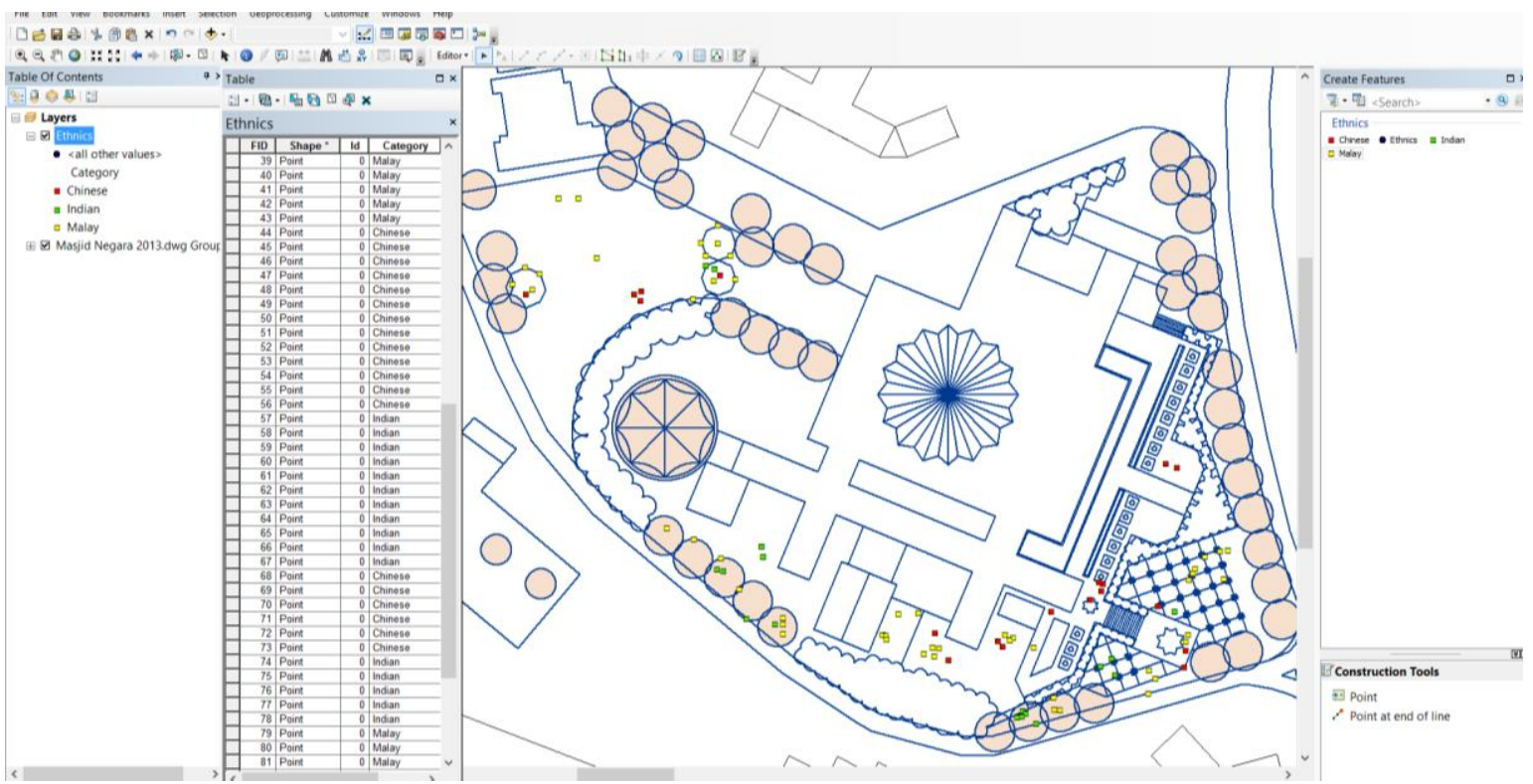

Fig. 4. Example: ArcGIS data of the National Mosque open spaces 
The process of digitization involved several sequence. As the process started with the manual mapping, it was then followed by several steps of transmitting the data into ArcGIS including re-mapping the physical maps. After the database with different attributes had been completely created, further analysis were conducted. Figure 5 on the next page elucidates the sequence of data digitization and analysis process in the ArcGIS.

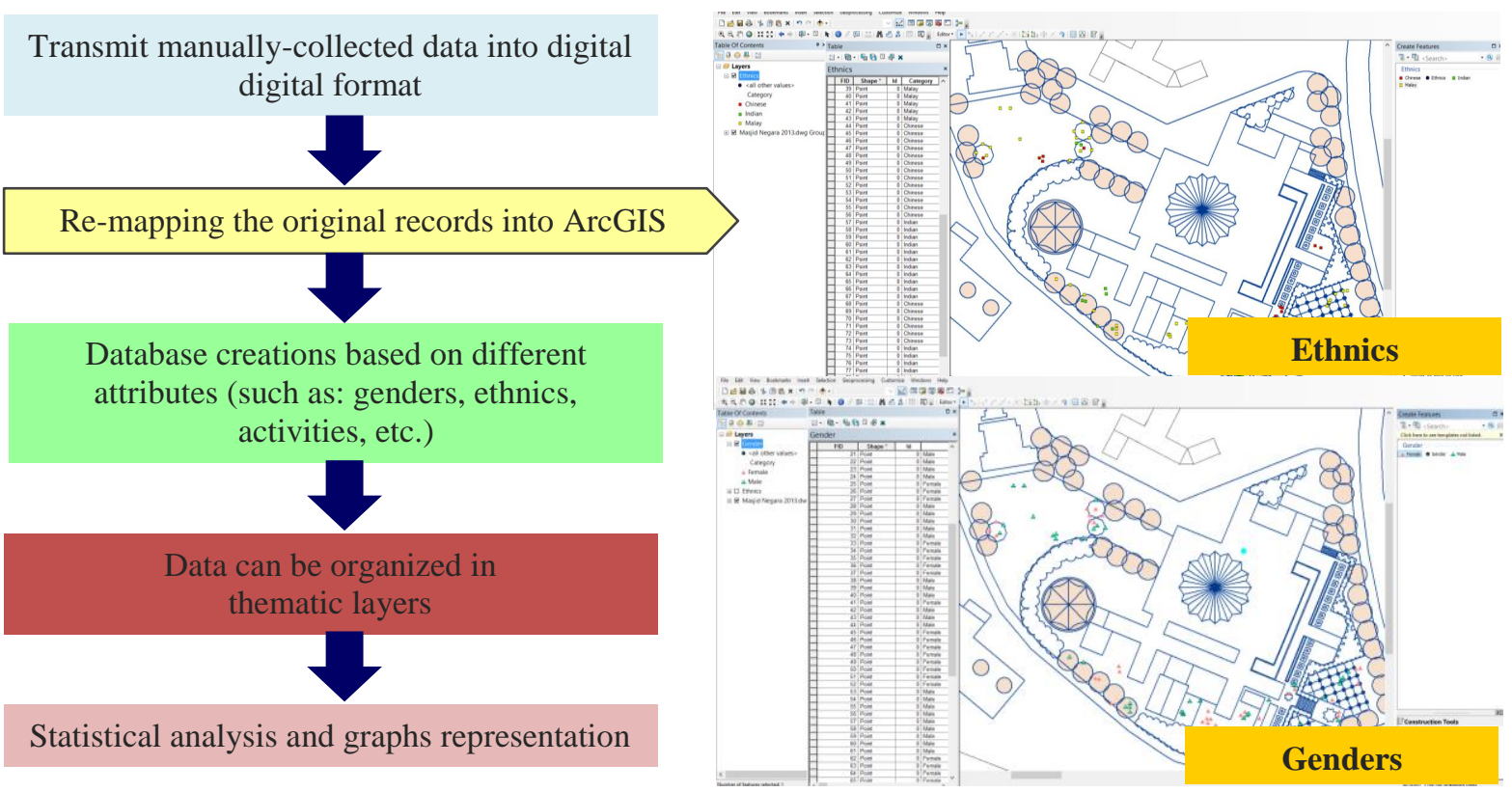

Fig. 5. Example: Digitized ArcGIS plans show a daily pattern of occupancy at National Mosque, stratified concerning gender and ethnicities

Since the systematic observation with behaviour mapping provides the qualitative information in exploring the spatial distinction of the mosque open spaces as civic open spaces, it is crucial to discover deeper into the subject matter qualitatively by engaging with the 'actors' who involve directly or indirectly in managing or utilising the mosque open spaces. Thus, the following subsection will describe the next method used for this study that is focus group discussion.

\subsection{Focus group discussion}

Focus group discussion is a part of qualitative data collection for this study. There are several groups of people selected from a broad range of target population, and these 'actors' are interviewed collectively regarding their opinions, perceptions, beliefs and suggestions towards the subject matter (Menter et al., 2011). About this research, the were three groups formed to be the participants of the discussions mainly mosque managers from each case study mosque, Muslim community as well as the nonMuslim community. Before conducting the focus group discussions, the researcher had established three different sets of question which will be used for each group. Different question sets were established due to the different backgrounds and needs of the participants that they might differ in revealing information that the researcher wishes to obtain. The discussions were divided into smaller groups for each participant. For instance, there were 12 participants in the Muslim group, but the researcher made two separate discussions to achieve optimum output from each discussion. The discussions normally took approximately an hour or more (lesser than two hours) depending on the participants' cooperation as well as the adequacy of information obtained throughout the discussions. Before the discussions started, the researcher distributed the participant cards to all the participants. The use of participant cards is important in helping the researcher to record their demographic information. Demographic information may have some significant relationship with the qualitative findings later on. Table 2 in the next page 
briefly explains the demographic backgrounds together with the frequencies of the participants involved in the focus group discussions:

Table 2. Demographic information of the focus group discussions' participants

\begin{tabular}{|c|c|c|c|c|}
\hline Demographic Information & Category & Mosque Managers & Muslim & Non-Muslim \\
\hline \multirow[t]{2}{*}{ Gender } & Male & 11 & 6 & 13 \\
\hline & Female & 1 & 6 & 10 \\
\hline \multirow[t]{5}{*}{ Age } & $20-29$ years old & 1 & 5 & 10 \\
\hline & $30-39$ years old & 5 & 2 & 5 \\
\hline & $40-49$ years old & - & 3 & 6 \\
\hline & $50-59$ years old & 1 & 2 & 2 \\
\hline & 60 years old and above & 5 & - & - \\
\hline \multirow[t]{4}{*}{ Ethnic } & Malay & 12 & 11 & \\
\hline & Chinese & - & 1 & 11 \\
\hline & Indian & - & - & 12 \\
\hline & Other & - & - & - \\
\hline \multirow[t]{5}{*}{ Religion } & Islam & 12 & 12 & \\
\hline & Buddha & & & 9 \\
\hline & Hindu & & & 8 \\
\hline & Christian & & & 6 \\
\hline & Other & & & - \\
\hline \multirow[t]{4}{*}{ Level of Education } & Primary education & - & - & - \\
\hline & Secondary education & 4 & - & 3 \\
\hline & Tertiary education & 5 & 12 & 12 \\
\hline & Not mentioned & 3 & - & 8 \\
\hline Total & & 12 & 12 & 23 \\
\hline
\end{tabular}

${ }^{\star}$ Mosque managers: four persons from the National Mosque, three persons from Abu Ubaidah Mosque and five persons from Al-Ghufran Mosque.

The focus group data was transcribed verbatim by using NVivo, and it was further analysed by using a qualitative analysis software, Quirkos. Quirkos is a powerful yet simple analysis tool that helps the researcher to sort and manage textual data. The analysis was conducted by extracting themes from the discussions with the focus group participants. By using Quirkos, the themes can be extracted from the transcripts and further created in the form of bubble diagrams as shown in Figure 6 below. It shows how the textual data was analysed (highlighted in the right pane) and later dragged into the thematic bubbles. The inputs in the thematic bubbles will then analysed in thematic analysis according to the emergent themes from the whole discussions.
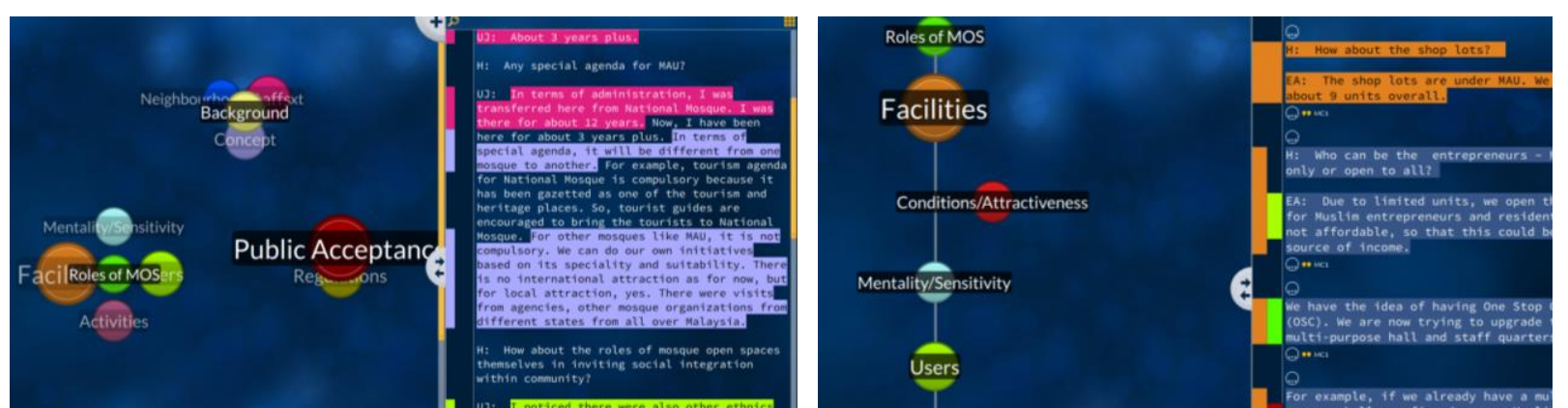
Fig. 6. The user interface of Quirkos software

\section{Opportunities and Drawbacks from the Methodology}

Based on the application of the mixed-methods; the systematic observation with behaviour mapping and the focus group discussions, many things can be learned to improve the whole process of the fieldwork as well as to achieve the objectives of the study. Some opportunities and drawbacks were identified after the pilot study and also during the actual fieldwork phase. As for the systematic observation and behaviour mapping, the researcher had to be anonymous during the observation to reduce bias. Even though it was quite challenging to maintain anonymous in the middle of the crowd especially when some of the mosque open space users felt curious seeing the researcher jotting down things, the researcher managed to do it well. However, it was a golden opportunity for the researcher to probe some questions to the users who approached the researcher due to their curiosity. On the other hand, working sans assistants was one of the challenges that the researcher faced. During some particular days of observation, the researcher had to strategize to work alone since the assistants were not available. Dealing with unpredictable weather in Kuala Lumpur was part of the challenges. The observation times somehow changed or delayed or even replaced. The vantage points for the observation became limited, especially during rainy days. Nonetheless, the researcher had the chance to see different the spatial occupancy of the mosque open spaces and the users' patterns when the site was raining. As for the focus group discussions, it was quite challenging facing outshined participants during the sessions. Since it is not appropriate to stop the participants from conveying ideas, it is the responsibility of the researcher to moderate the discussions in balance with all participants. Last minute cancellations by the participants were challenging too. Since it happened once to the researcher, the thought of having a contingency, or backup plan was very crucial. From the opportunities, challenges and mitigation drawn above, it can be learned that having proper strategies and planning during the actual fieldwork are important for this study as well as for future research.

\section{Conclusion}

To conclude, this paper focuses the valuable insights of a mixed-method application; including the data gathering process as well as the method of analysis. Having described those applications, the combination of the systematic observation with behaviour mapping and focus group discussions in this study had generated extensive spatial and social findings of the urban mosque open spaces in Kuala Lumpur, Malaysia. The use of ArcGIS software for spatial analysis and Quirkos software for qualitative analysis has given a significant impact on this study; they are powerful in aiding the researcher to visualise and present the spatial findings in a systematic manner, as well as to articulate the emergent themes of the qualitative findings in a well-comprehended visual form.

\section{Acknowledgements}

The author would like to thank Ministry of Education of Malaysia, International Islamic University Malaysia and Edinburgh College of Art, The University of Edinburgh for their continuous support throughout the whole process of this doctoral research. 
Special thanks to the author's supervisors from Edinburgh School of Architecture and Landscape Architecture, Edinburgh College of Art, The University of Edinburgh for their guidance in making this research success. May Allah reward each and every one of them who directly and indirectly involved in it.

\section{References}

Aazam, Z. (2005). The social logic of the mosque: A building and urban spatial investigations. In Proceedings of The 5th International Space Syntax Symposium, $1-4$.

Baharudin, N. 'Athiqah, \& Ismail, A. S. (2014). Communal mosques: Design functionality towards the development of sustainability for community. Procedia Social and Behavioral Sciences, 153, 106-120. doi:10.1016/j.sbspro.2014.10.046.

Bryman, A. (2012). Social research methods (Fourth.). New York: Oxford University Press Inc.

Cosco, N. G., Moore, R. C., \& Islam, M. Z. (2010). Behavior mapping: A method for linking preschool physical activity and outdoor design. Medicine and Science in Sports and Exercise. doi:10.1249/MSS.0b013e3181cea27a.

Dewiyanti, D., \& Kusuma, H. E. (2012). Spaces for Muslims and spiritual meanings. Procedia - Social and Behavioral Sciences, 50, 969-978. doi:10.1016/j.sbspro.2012.08.098.

Fukami, N., \& Sato, S. (2012). Islam and multiculturalism: Between norms and forms. JSPS Asia and Africa science platform program, Organization for Islamic area studies, Waseda University. Retrieved from https://books.google.co.uk/books?id=H1asMwEACAAJ.

Ismail, F. (2002). The Eid prayer in South Africa and Muslim women's struggle for sacred space. Annual Review of Islam in South Africa, 5, 36-39. Retrieved from http://web.uct.ac.za/depts/religion/documents/ARISA/2002_M5_farhana.pdf.

Mansor, M., Zakariya, K., \& Harun, N. Z. (2015). Urban public space in Kuala Lumpur. Kuala Lumpur: IIUM Press.

Marusic, B. G., \& Marusic, D. (2012). Behavioural maps and GIS in place evaluation and design. In B. M. Alam (Ed.), Application of Geographic Information Systems (pp. 113-138). INTECH Open Access Publisher. Retrieved from http://cdn.intechopen.com/pdfs/40505/InTech-

Behavioural_maps_and_gis_in_place_evaluation_and_design.pdf.

Mohamad Rasdi, M. T. (2010). Rethinking Islamic architecture. Strategic information and research development centre. Retrieved from https://books.google.co.uk/books?id=dsDCSAAACAAJ.

Mohamad Rasdi, M. T., \& Utaberta, N. (2010). The design of mosques as community development centers from the perspective of the Sunna and wright's organic architecture. Journal of Islamic Architecture, 1(1), 1-7.

Mohamed Kamal Ismail, K. A. (2010). Sultan Hassan Mosque: An Islamic architectural wonder analytical study of design and its effect on Islamic Cairo.pdf. Journal of Islamic Architecture, 1(2), 94-105.

Mohyuddin, A., \& Lamit, H. (2008). Users' place experience of a contemporary masjid towards urban place-making in Singapore. In Users' Place Experience of a Contemporary Masjid Towards Urban Place-Making in Singapore, 49-57.

Moore, R. C., \& Cosco, N. G. (2010). Using behaviour mapping to investigate healthy outdoor environments for children and families: Conceptual framework, procedures, and applications. In C. Ward Thompson, P. Aspinall \& S. Bell (Eds.),Open Space, People Space 2: Innovative Approaches to Researching Landscape and Health (pp. 33-72). London: Taylor \& Francis.

Musytari, M. I., \& Jasmi, K. A. (2008). Pengimarahan masjid dalam agenda ummah. Skudai: Penerbit Universiti Teknologi Malaysia.

Najafi, M., \& Mohd Shariff, M. K. (2011). Factors influencing public attachment to mosques in Malaysia. Archnet-IJAR, 5(3), 7-24.

Najafi, M., \& Sharif, M. (2011). Public attachment to religious places: A study of place attachment to mosques in Malaysia. Environmental Psychology, 8(1), 299310.

Omer, S. (2009). The Prophet Muhammad (PBUH) and urbanization of Madinah (Second.). Kuala Lumpur: IIUM Press. 
Omer, S. (2013). A code of conduct for establishing and using mosques. Islamic city. Retrieved from http://www.islamicity.org/5260/a-code-of-conduct-forestablishing-and-using-mosques/.

Salama, A. M., \& Salama, A. M. (2008). When good design intentions do not meet users expectations: Exploring Qatar University campus outdoor spaces. International Journal of Architectural Research, 2(2).

Sirat, M., \& Abdullah, A. (2007). Mosques as a type of civic space in turbulent times: A case study of globalizing Kuala Lumpur. In M. Douglass, K.C. Ho \& G.L.Ooi (Eds.), Globalization, the city and civil society in Pacific Asia: The social production of civic spaces (pp. 104-120). London \& New York:Taylor \& Francis.

Tamuri, A. H., Ismail, M. F., \& Jasmi, K. A. (2012). A new approach in Islamic education : Mosque based teaching and learning. Journal of Islamic and Arabic Education, 4(1), 1-10.

Vasilevska, L. (2012). Towards more user-friendly public open space in low-rise high-density housing areas. Proceedings of 1st International Conference on Architecture \& Urban Design, 1-10. Retrieved from http://icaud.epoka.edu.al/res/1_ICAUD_Papers/1ICAUD2012_Ljiljana_Vasilevska.pdf.

Ward Thompson, C. (2002). Urban open space in the 21st century. Landscape and Urban Planning, 60(2002), 59-72. doi:10.1016/S0169-2046(02)00059-2. 